REVISTA DE DERECHO UNED, NÚM. 14, 2014

\title{
LAS NORMAS INTERNACIONALES CONVENCIONALES DE DERECHOS HUMANOS Y SU CONTRIBUCIÓN AL ORDEN PÚBLICO INTERNACIONAL
}

\author{
CONVENTIONAL INTERNATIONAL HUMAN RIGHTS AND \\ THEIR CONTRIBUTION TO INTERNATIONAL PUBLIC ORDER
}

ELBA JimÉNEZ SOLARES

Profesora de Derecho Internacional en la Facultad de Derecho de la

UNAM y Doctora en Derecho por la UNED

ejimenezs@derecho.unam.mx

Resumen: El desarrollo de las normas internacionales convencionales en materia de derechos humanos ha impactado profunda y significativamente en los ordenamientos internos. El reconocimiento e incorporación de estas normas en los órdenes nacionales indudablemente ha empujado hacia la construcción de un cierto grupo de normas que constituyen un Derecho uniforme, común, fundamental y vinculante a todos los órdenes existentes y que contribuyen a la conformación de lo que podemos denominar como orden público internacional. Por supuesto, este orden público internacional no se compone exclusivamente de normas de derechos humanos, pero sí de una gran mayoría de ellas, por lo que su desarrollo ha contribuido a la definición del contenido del mismo.

Palabras clave: Normas internacionales convencionales, Orden público internacional, Derechos Humanos, Tratados internacionales de derechos humanos, Derecho uniforme.

Abstract: The development of conventional international standards on human rights has impacted significantly deeper and domestic legislation. The recognition and incorporation of these standards into domestic orders undoubtedly has pushed the construction of a certain 
set of rules that constitute a uniform law, common, fundamental and binding on all existing orders and contribute to the creation of what we call as international public order. Of course, this international public order is not composed exclusively of human rights standards, but a vast majority of them and their development has contributed to the definition of the content of this concept.

Keywords: Conventional International Standards International public order Human Rights International human rights treaties uniform law

Recepción original: 16/01/2014

Aceptación original: 19/02/2014

Sumario: I. Introducción. II. Antecedentes del orden público internacional. III. El desarrollo del orden público internacional; 3.1. En América; 3.2 En Europa. IV. Las normas de Derechos Humanos convencionales como parte de un orden público general. V. Breves consideraciones en torno al contenido del orden público internacional. VI. Conclusiones.

\section{INTRODUCCIÓN}

El desarrollo de las normas internacionales convencionales de derechos humanos está produciendo un fenómeno jurídico de gran relevancia a nivel mundial. Este consiste en la creación de un conjunto de normas uniformes y comunes a todos los órdenes jurídicos existentes, nacionales y supranacionales. Dichas normas son consideradas fundamentales y por ende, se les atribuye un alto grado de legitimidad y vinculatoriedad por parte de los miembros de la comunidad internacional. Esta uniformidad del derecho está conduciendo, asimismo, hacia la armonización de las relaciones existentes entre los diferentes órdenes jurídicos.

A nuestro parecer, se está dando un proceso de integración del derecho, mismo que ha cobrado un gran impulso mediante la celebración, incorporación y aplicación de tratados internacionales de derechos humanos en los diferentes ordenamientos nacionales. En los últimos años, la creación, adopción y desarrollo de normas y conceptos jurídicos internacionales en materia de derechos humanos por parte de los principales creadores de la normatividad internacional, a saber, los Estados, las organizaciones y los tribunales internacionales, ha propiciado la conformación del núcleo duro del Derecho y y el surgimiento de otro 
concepto jurídico que, si bien aún está en proceso de conformación, es cada vez más invocado: el orden público internacional.

\section{ANTECEDENTES DEL ORDEN PÚBLICO INTERNACIONAL}

La institución del orden público internacional a que se hace referencia en el derecho internacional es un concepto que tiene varias acepciones. En principio, debemos diferenciarlo de aquél concepto acuñado en el ámbito nacional y del concepto derivado en el ámbito del Derecho Internacional Privado.

Originalmente, el orden público fue concebido en el orden nacional como una institución jurídico-política dedicada a salvaguardar los principios, valores e intereses más esenciales del Estado, mismos que podían versar sobre diversos tópicos de carácter jurídico, económico, social, cultural, religioso y político, por lo que no era raro que se le asimilara a conceptos tales como la soberanía, la supremacía estatal, la seguridad pública o la seguridad nacional, por citar los más relevantes. En este orden de ideas, en el ámbito nacional, el orden público fue referido fundamentalmente en torno a los conceptos Estado y Soberanía nacional.

Desde entonces y hasta nuestros días, en el derecho doméstico el orden público es un término difícil de definir dada la diversidad de su contenido, ya que como señalamos refleja los valores, intereses y aspectos más relevantes y esenciales de un Estado y de su pueblo, por lo que su contenido es numeroso y variable, según el grado de desarrollo de cada pueblo. Por otro lado, cabe destacar que, además de los aspectos ya señalados, el orden público estatal está en constante cambio, va evolucionando también, de ahí que varíe de una época a otra, por lo que no es extraño encontrar diferencias aún entre órdenes públicos dentro de un mismo país o región y de una época a otra.

Como consecuencia de las interacciones jurídicas entre los Estados y sus individuos con los demás miembros de la comunidad internacional, hubo la necesidad de regular, dentro de su territorio, los efectos jurídicos de los actos realizados en el extranjero; ello, con el fin de proteger a las instituciones jurídicas consideradas fundamentales. Es así como surge el Derecho internacional privado o Conflictual, cuyo objeto principal es establecer reglas claras para regular la aplicación extraterritorial de las normas extranjeras y evitar confrontaciones entre ordenamientos jurídicos nacionales, así como también para procurar la cooperación internacional en materia procesal, entre los Estados. En ese orden de ideas, hubo la necesidad de establecer algunos supuestos 
normativos en los que, de manera excepcional, se pudiera excluir la aplicación extraterritorial de cualquier norma extranjera y, en un momento dado, determinar la aplicación absoluta y exclusiva de las normas nacionales, para sí tutelar dentro de su ordenamiento, jurídico valores o principios jurídicos considerados fundamentales. Es así como surgió el orden público internacional en el derecho internacional privado como un instrumento protector del ordenamiento jurídico nacional.

Visto así, el orden público internacional funge como un muro de contención para la protección y preservación de normas o conceptos jurídicos fundamentales, esenciales, intocables y supremos dentro del ordenamiento jurídico de un Estado soberano. El orden público internacional en tanto instrumento protector tiene como función principal limitar o anular los efectos que pudieran tener, dentro de su ordenamiento, las normas extranjeras y/o actos jurídicos realizados en el extranjero, fundado en la potestad soberana estatal.

En este orden de ideas, encontramos algunos criterios de tribunales nacionales tales como el mexicano, quien en una tesis ${ }^{1}$ define al orden público internacional como un concepto jurídico indeterminado, que se actualiza en cada caso concreto, es relativo y su función consiste en atender las reglas mínimas de convivencia social, de tal forma que los jueces al identificarlo, deben fundarse en elementos objetivos que reflejen las preocupaciones de la sociedad mexicana y al mismo tiempo, no obstaculicen el disfrute de los derechos de terceros.

Posteriormente, a nivel internacional, el desarrollo de los derechos humanos fue incidiendo en este concepto y motivó a tomar como referente ya no sólo al Estado, sino al individuo. Este mismo fenómeno se dio con las garantías individuales y sociales o constitucionales y los derechos humanos en el orden interno.

Este movimiento consistente en la humanización del derecho, ha conducido a que otros ordenamientos nacionales incorporen en su

${ }^{1}$ En México existe una tesis sobre el particular de un Tribunal Colegiado de Circuito: Tesis Aislada, 9a. Época; en Semanario Judicial de la Federación y su Gaceta; Tomo XXII, Agosto de 2005; Pág. 1956. «Orden Público. Es un concepto jurídico indeterminado que se actualiza en cada caso concreto, atendiendo a las reglas mínimas de convivencia social. ... un concepto jurídico indeterminado de imposible definición cuyo contenido sólo puede ser delineado por las circunstancias de modo, tiempo y lugar que prevalezcan en el momento en que se realice la valoración... para darle significado, el juzgador debe tener presentes las condiciones esenciales para el desarrollo armónico de la comunidad, es decir, las reglas mínimas de convivencia social; en la inteligencia de que la decisión que se tome en el caso específico no puede descansar en meras apreciaciones subjetivas, sino en elementos objetivos que traduzcan las preocupaciones fundamentales de la sociedad, siempre buscando no obstaculizar la eficacia de los derechos de tercero.» 
concepto de orden público, los derechos del individuo, tal como sucedió en España, cuyo Tribunal Constitucional se refirió a éste como el conjunto de normas y principios que, en un momento histórico determinado, refleja el esquema de valores esenciales a cuya tutela atiende de una manera especial, cada ordenamiento jurídico concreto, considerando que dicho concepto está influenciado además, por los derechos fundamentales contenidos en la Constitución ${ }^{2}$.

En la doctrina algunos juristas siguieron este mismo criterio. Por ejemplo, Salvador Pérez expresó que el contenido del orden público constitucional español se aglutina en torno a dos aspectos fundamentales: 1) La existencia de valores comunes a toda la humanidad, es decir, los derechos fundamentales, las libertades públicas y otros derechos constitucionalmente reconocidos; y 2) Los principios constitucionales que reflejan los valores esenciales de la comunidad y son aquellos valores axiomáticos, es decir, los que informan el Estado Social y Democrático de Derecho y que constituyen el fundamento del orden político y de la paz social. ${ }^{3}$

Si bien, los conceptos de orden público de los tribunales nacionales arriba citados, divergen considerablemente, tienen un común denominador y es que ambos buscan limitar o contrarrestar los efectos de las normas extranjeras en el orden interno, bien sea bajo argumentos relacionados con la protección del Estado y sus instituciones o bien sea con relación a la protección del individuo y sus derechos fundamentales o humanos.

No obstante lo anterior, el término orden público internacional también es invocado en el campo del Derecho internacional público, particularmente, en materia de Derechos humanos. Así por ejemplo, encontramos que este concepto ha sido referido por el Tribunal Europeo de

2 ... el TC ha dejado claro que «este concepto de orden público ha adquirido una nueva dimensión a partir de la vigencia de la Constitución de 1978. Aunque los derechos fundamentales y las libertades públicas que la Constitución garantiza solo alcanzan plena eficacia allí donde rige el ejercicio de la soberanía española, nuestras autoridades públicas, incluidos los jueces y tribunales, no pueden reconocer ni recibir resoluciones dictadas por autoridades extranjeras que supongan una vulneración de los derechos fundamentales y libertades públicas garantizados constitucionalmente a los españoles o, en su caso, a los españoles y extranjeros. El orden público del foro ha adquirido así en España un contenido distinto, impregnado en particular por las exigencias del artículo 24 de la Constitución». Sentencia del Tribunal Constitucional 43/1986, de fecha 15 de abril de 1986. Fundamento jurídico número 4. Texto disponible en http://www.legalsolo.com/ShowSentencia.do?sentenciaId=STC1986-043\&sente nciaType $=$ Sentencia\&text $=$ STC $+23 \% 2 F 2008$ Cfr. PÉREZ ÁlvAREZ, Salvador, «Las tradiciones ideológicas islámicas ante el repudio. Su eficacia civil en el derecho del estado español», en ILU, Revista de ciencias de las Religiones, 2008, número 13, p. 217.

${ }^{3}$ Pérez Álvarez, S., op. cit., pp. 218 y 219. 
Derechos Humanos y por la Corte Interamericana de Derechos Humanos, instancias supranacionales que poco a poco han ido contribuyendo, a través de sus resoluciones, a la determinación de su contenido.

El orden público internacional acuñado en el Derecho internacional de los Derechos Humanos está aún en proceso de conformación. Dado su contenido, se le ha asimilado en ocasiones con el Derecho Internacional global ${ }^{4}$, el ius commune, el orden común, el orden público de la comunidad ${ }^{5}$, el orden público sustantivo ${ }^{6}$, el orden público europeo o el orden público americano, el orden constitucional global, etcétera, por citar algunos términos afines.

Asimismo, dados sus efectos, a este concepto se le suele confundir también con el de norma de ius cogens internacional y norma erga omnes, sin embargo, consideramos que no necesariamente son conceptos equivalentes, sino que más bien se trata de una característica de las normas de orden público. En otras palabras, las normas que forman parte del orden público internacional tienen o producen estos efectos dentro del ordenamiento jurídico en general ${ }^{7}$ pero no necesariamente son idénticas entre ellas.

En nuestra opinión el orden público internacional, hoy en día, es un concepto jurídico aún indefinido y también muy amplio, pues lo mismo se enfoca a los derechos humanos y a la protección del individuo en sus diversas manifestaciones, que al mantenimiento de valores o principios superiores existentes y reconocidos como tales dentro del ordenamiento

${ }^{4}$ Cfr. Martín ARRIBAS, Juan José, «Hacia un Derecho Internacional global en los albores del siglo XXI», en Anuario de Derecho Constitucional Latinoamericano, tomo II, año 11, Editado por Fundación Konrad-Adenuaer-Stinftung E. V., Uruguay, 2005, pp. 637-671.

${ }^{5}$ Cfr. De Rosas, Pablo Enrique, «Ponencia Orden público internacional. Tendencias contemporáneas. Orden público en el ordenamiento del Mercosur», en XXVI Seminario Nacional de Derecho Internacional Privado y Comparado, Profr. Friedrich K. Juenguer, Academia Mexicana de Derecho Internacional Privado y Comparado, A. C., México, Universidad Iberoamericana de Tijuana, México, p. 5. http://www.amedip. org/pdf/DeRosasPabloEnrique. PDF

${ }^{6}$ Mezgravis, Andrés A., «El orden público sustantivo, el orden público procesal y la arbitrabilidad como causales de denegación del laudo: especial referencia a Venezuela y otros países de América Latina», en Arbitraje Comercial y Arbitraje de Inversión, la Convención de NY 50 años después, Instituto Peruano de Arbitraje, Perú, 2009, pp. 1-35. http://www.mezgravis.com/El-orden-pub-vf-rev-07-08.pdf

${ }^{7}$ Antonio Gómez Robledo refiere que, en el Derecho internacional, desde sus inicios, se ha asimilado al ius cogens al concepto de orden público internacional: «... El Pacto, en efecto, configura por primera vez la idea de un orden público internacional, expresión sinónima o en todo caso coextensiva a la concepción del ius cogens.» GóMEz Robledo, Antonio, El Ius Cogens Internacional, Estudio histórico-crítico, [en línea], México, Instituto de Investigaciones Jurídicas, 2009, http://www.bibliojuridica. org/libros/libro.htm?l=1073, ISBN 970-32-0813-4, p. 54. 
jurídico internacional, y que además son comunes a los diferentes ordenamientos jurídicos nacionales y supranacionales existentes. Tratemos de identificar algunas otras normas que conforman su contenido.

Maurice Kamto refiere que el orden público internacional se compone de normas de importancia fundamental para la comunidad internacional que no pueden ser derogadas por normas convencionales, so pena de nulidad y que dichas normas, en su momento, han constituido un paso importante para ir de un Derecho Internacional clásico, -que se concebía como un derecho de coordinación de soberanías y un derecho intersubjetivo de relaciones interestáticas- a un Derecho Internacional objetivo, más avanzado y moderno, donde existen ciertas normas que deben ser ineludiblemente cumplidas y que no pueden derogarse. Además de lo anterior, las obligaciones contenidas en dichas normas son para con la comunidad en su conjunto. En consecuencia, las violaciones a dichas normas representan no solamente atentados a ciertos sujetos o grupos, sino a toda la comunidad, es decir, son actos en contra del orden público internacional, mismo que está basado en un cierto número de valores fundamentales y comunes a todas las naciones y a la especie humana. ${ }^{8}$

Por su parte, Monroy Cabra considera que este concepto «sugiere un conjunto de normas tendentes a salvaguardar la seguridad, la estabilidad, la paz, la salubridad y, en general, el interés comunitario y el bien común.» ${ }^{9}$ Estas acepciones nos parecen bastante acertadas, ya que hoy en día, el orden público internacional además de denotar la existencia de ciertas normas comunes, fundamentales, esenciales,

${ }^{8} C f r$. "Parler $d d$ ' "ordre public international» signifie qu'il existe en droit international puiblic un ensamble de "règles d'importance fondamentale pour la communauté internationales dans son ensemble auxquelles les Etats ne pourraient, à peine de nullité, déroger par des conventions contraires». "Cette notion d'ordre public international marque la sortie du droit international classique qui a prévalu jusqu'au début du XXe siècle, et qui était exclusivement un droit de coordination des souveranités. Elle rompt avec la nature purement intersubjective des relations interétatiques et du droit international, et laîsse apparaitre progressivement un droit international objectif auquel les parties ne peuvent déroger, parce que les obligations qu'il dévoile sont prises à l'égard de la communauté international dans son ensamble. Par conséquent, leur violation recevrait la sanction de la responsabilité, car il s'agirait «de comportements portant atteinte, au moins autant qu'aux droits subjectifs de tel Etat particulier, à un ordre public international»... La notion d'ordre public international est fondée sur l'idée essentielle qu'il existe dans la socie'te internationales contemporaine un certain nombre de valeurs fondamentales communes à toutes les nations et à toute l'espèce humaine. Ces valeurs peuvent se regrouper autour de deux idées majeures: sacralisation de l'homme et exaltation de l'humanité.» Kамто, Maurice, «Volonté de l'État et ordre public International», Recueil des Cours de Droit International, tomo 310, París, 2004, pp. 313 y 314.

${ }_{9}^{9}$ Monroy Cabra, M. G., Tratado de Derecho Internacional Privado, sexta edición, Bogotá, Colombia, Editorial Temis, 2006, p. 271. 
universales e imperativas, son normas que importan aspiraciones comunes a todo orden o sistema jurídico, o mejor dicho, a todo grupo social existente con independencia del orden jurídico nacional o supranacional de que se trate.

Ambos autores, nos dan algunas luces en cuanto al contenido de las normas de orden público internacional, según sus caracteres, función, efectos y fin que las normas persiguen. Esta figura jurídica, indudablemente, además de lo anterior, contiene normas que persiguen otros fines superiores en el orden internacional, tales como el respeto y la preservación a la soberanía nacional, el mantenimiento de la paz y la seguridad internacionales, la solución pacífica de las controversias, la libre autodeterminación de los pueblos, etcétera, así como también la protección y respeto a las normas de derechos humanos, por citar las más relevantes.

De lo anterior, podemos inferir que el orden internacional al igual que cualquier figura jurídica, debe tener un fin específico y fundamental que es el ser un sistema creado al servicio del individuo en tanto que éste es el principal sujeto del derecho internacional y creador del mismo. El derecho es un instrumento y como tal debe estar al servicio de su creador.

Visto así, el desarrollo del concepto del orden público internacional, debe encontrar, por un lado, su justificación en la necesidad de contar con elementos mínimos que contribuyan a la supervivencia y mantenimiento del ordenamiento jurídico internacional y al mismo tiempo el bienestar de los miembros de la comunidad internacional. Visto así, es tan importante, la preservación de los derechos del individuo y del Estado como el mantenimiento del sistema jurídico internacional en general, vía la preservación de la paz y la seguridad internacionales. ${ }^{10}$

Según Claudio Nash, las ideas de Kant y su tesis acerca de un cosmopolismo universal, han tenido una gran influencia en el desarrollo de un derecho internacional vinculado con los derechos humanos. En su opinión, los planteamientos de Kant están claramente expresados en el ideal contemporáneo de un «orden público internacional» que está ba-

${ }^{10}$ Un ejemplo de un caso de violación a los derechos humanos dentro de un Estado, que puede poner en peligro la paz y la seguridad internacionales, en una región, se encuentra en la reciente Resolución del Consejo de Seguridad de las Naciones Unidas, No. 688 de 1991, de fecha 5 de abril del mismo año. Resolución que resulta un tanto criticable dado que en la realidad, muchos países bajo el argumento de intervenir para proteger los derechos humanos o para realizar una intervención humanitaria en un país determinado, han llegado a cometer muchos excesos y ha resultado ser a final de cuentas una forma de expansión de sus zonas de influencia y sometimiento a otros países. http://www.acnur.org/biblioteca/pdf/1981.pdf 
sado en el respeto y la protección a los derechos humanos, en el marco de un orden internacional fundado, a su vez, en las soberanías estatales mismas que confluyen en una organización supranacional como la ONU que está regida por el derecho internacional público, así como también en un orden fundado en el actuar de Estados legitimados por según la protección y respeto que brindan a los derechos humanos. ${ }^{11}$

En este orden de ideas, consideramos que el concepto de orden público internacional, indudablemente habrá de ir referido al respeto y protección de las normas jurídicas con contenidos de derechos humanos, en virtud de que son catalogadas, en forma generalizada, como valiosas en el ámbito internacional.

Para la Comisión de Derecho Internacional, ${ }^{12}$ este orden público internacional encuentra su antecedente en las normas imperativas de ius cogens, debido a que las normas que son calificadas como de orden público internacional, tienen estos efectos en los sistemas jurídicos existentes, así como una atribuida imperatividad y el consecuente rechazo a la dispositividad de las mismas por los sujetos destinatarios. En consecuencia, el orden público internacional constituye también una forma de limitar la voluntad estatal soberana en el ámbito supranacional.

\section{EL DESARROLLO DEL ORDEN PÚBLICO INTERNACIONAL}

\subsection{En América}

La referencia a este concepto la ubicamos en varias opiniones consultivas y resoluciones de la Corte Interamericana de Derechos Humanos (CoIDH), así como en el Reglamento de la CoIDH, bajo la acepción Orden público interamericano de los derechos humanos ${ }^{13}$.

${ }^{11}$ Nash RoJas, Claudio, «La protección Internacional de los Derechos Humanos, Chile», publicado por el Centro de Derechos Humanos de la Universidad de Chile, 2006, versión corregida de las conferencias dictadas en el marco del Seminario Internacional, El Sistema Interamericano de Protección de los Derechos Humanos y su repercusión en los órdenes jurídicos nacionales, organizado por la Corte Interamericana de Derechos Humanos y la Suprema Corte de Justicia de México, dirigida a funcionarios de la Suprema Corte, México D. F., (1 y 2 de febrero 2006), p.171. http://www. cdh.uchile.cl/media/publicaciones/pdf/27.pdf

${ }^{12}$ VARÓN MeJía, Antonio, "Orden público internacional y normas «ius cogens»: una perspectiva desde la comisión de Derecho Internacional y la Convención de Viena de 1969», en Diálogos de saberes: investigaciones y ciencias sociales, Universidad Libre, ISSN 0124-0021, N. ${ }^{\circ} 32$, Colombia, 2010, pp. 211-229. http://dialnet.unirioja. es/servlet/articulo?codigo $=3295808$

${ }^{13}$ Artículos 35.1, inciso f y 52.3 ambos del Reglamento de la Corte Interamericana de Derechos Humanos 
En su momento, la CoIDH definió al orden público estatal como el «conjunto de condiciones que aseguran el funcionamiento armónico y normal de instituciones sobre la base de un sistema coherente de valores y principios» ${ }^{14} \mathrm{y}$ lo contrapuso con el concepto de orden público interamericano, mismo que se relaciona con cuestiones de respeto y protección a los derechos humanos, así como también, con la existencia de un orden constitucional a nivel internacional. En ese sentido, el orden público americano estaría compuesto de valores y principios de derechos humanos en cuya cúspide se ubicarían las normas de ius cogens. ${ }^{15}$

Es de destacar que, en su momento, este tribunal expresó que constituyen una cuestión de orden público interamericano el interés superior del menor o el derecho a la no discriminación ${ }^{16}$, así como otras cuestiones de derechos humanos, calificándolos como un fundamento básico del ordenamiento jurídico en general, en tanto que se trata de valores comunes y superiores.

En esa tesitura, este mismo tribunal calificó al ejercicio de la función consultiva como una cuestión de orden público al considerar que como su objeto era la protección de los derechos humanos, su ejercicio resultaba indispensable para el cumplimiento de dicho cometido. ${ }^{17}$

Cabe comentar que si bien un gran número de normas internacionales de derechos humanos han sido consideradas como integrantes del orden público internacional, no por ello, podemos afirmar que este orden público se compone exclusivamente de ellas; también, puede contener normas con otros contenidos jurídicos igualmente fundamentales y propios del sistema jurídico en el que actúan como son la soberanía del Estado, su personalidad jurídica, el principio de legalidad, la irretroactividad de las normas, etc.

${ }^{14}$ CORTE INTERAMERICANA DE DERECHOS HUMANOS, Opinión Consultiva OC-5/85, del 13 de noviembre de 1985, La Colegiación obligatoria de periodistas (artículos 13 y 29 de la Convención Americana sobre Derechos Humanos) solicitada por el Gobierno de Costa Rica, http://www.corteidh.or.cr/docs/opiniones/seriea_05_esp.pdf

${ }^{15}$ Cfr. Aguilar Cavallo, Gonzalo, «La Corte Interamericana de Derechos Humanos y los derechos sociales», Revista Iberoamericana de Derecho Procesal Constitucional, número 13, enero-junio, Editada por el Instituto Iberoamericano de Derecho Procesal Constitucional, México, 2010, p. 12. http://www.iidpc.org/revistas/13/pdf/19_76.pdf

${ }^{16}$ Resolución del Presidente de la Corte Interamericana de Derechos Humanos, de 7 de julio de 2011, Caso Atala Riffo e hijas vs. Chile: «...la Comisión identificó como de orden público interamericano [el tema] relativo al principio del interés superior de los niños y niñas desde las diferentes perspectivas que presenta el caso». http://www. corteidh.or.cr/docs/asuntos/atala.pdf

${ }^{17}$ Cancado Trinidade, Antonio Augusto, Derecho Internacional de los Derechos Humanos, esencia y trascendencia (votos en la Corte Interamericana de Derechos Humanos, 1991-2000), Editorial Porrúa, México, 2007, pp.14, 49 a 51, 81 a 82, 84 y sigs. 


\subsection{En Europa}

La Corte Europea de Derechos Humanos en su momento, ha hecho referencia a la Convención Europea calificándola como un »instrumento constitucional del orden público europeo ${ }^{18}$ y señaló que el objetivo del Convenio Europeo era el establecimiento de un orden público para la protección de los seres humanos. ${ }^{19}$

Además de lo anterior, ese mismo Tribunal, en el caso Soering ${ }^{20}$ expresó que el objeto de esta Convención era el constituir un instrumento para la protección colectiva de los derechos humanos. Por tanto, podemos inferir que al igual que en América, el concepto de orden público también se encuentra referido a la protección y respeto de las normas de derechos humanos en dicha región.

Por otro lado, en el caso Pfunders (Austria contra Italia), la Comisión Europea de Derechos humanos expresó que el propósito de la Convención Europea era el establecimiento de un «orden público común» de las democracias libres de Europa. ${ }^{21}$

Por todo lo anterior, podemos afirmar que las instituciones europeas, han considerado al orden público internacional bajo la concepción de una especie de orden constitucional internacional, respetuoso y protector de los derechos humanos.

${ }^{18}$ Caso Loizidou vs. Turquia, de 1995. http://www.corteidh.or.cr/docs/libros/FixVol1.pdf y http://www.corteidh.or.cr/docs/libros/FixVol2.pdf

${ }_{19}$ DulitzKy, Ariel E., Los Tratados de derechos humanos en el constitucionalismo iberoamericano, www.bibliojuridica.org/libros/5/2061/10.pdf p. 137.

${ }^{20}$ CASE OF SOERING v. THE UNITED KINGDOM, Application no. 14038/88, JUDGMENT, 07 July 1989. Párrafo 87. In interpreting the Convention regard must be had to its special character as a treaty for the collective enforcement of human rights and fundamental freedoms (see the Ireland v. the United Kingdom judgment of 18 January 1978, Series A no. 25, p. 90, § 239). Thus, the object and purpose of the Convention as an instrument for the protection of individual human beings require that its provisions be interpreted and applied so as to make its safeguards practical and effective (see, inter alia, the Artico judgment of 13 May 1980, Series A no. 37 , p. 16, § 33). In addition, any interpretation of the rights and freedoms guaranteed has to be consistent with "the general spirit of the Convention, an instrument designed to maintain and promote the ideals and values of a democratic society» (see the Kjeldsen, Busk Madsen and Pedersen judgment of 7 December 1976, Series A no. 23, p. 27, § 53).

http://cmiskp.echr.coe.int/tkp 197/view.asp?item=1\&portal=hbkm\&action=html\&hig hlight=Soering\&sessionid=18397457\&skin=hudoc-EN

${ }^{21}$ LÓPEZ HurTado, Carlos, ¿Un régimen especial para los tratados de derechos humanos dentro del Derecho Internacional?, www.revistas.unam.mx/index.php/amdi/ article/.../16365 p. 279. 
En este mismo sentido se han expresado algunos doctrinarios tales como López Hurtado, quien refiere que este concepto está basado en la absoluta primacía y respeto a ciertas normas y valores fundamentales ${ }^{22}$, valores además comunes ${ }^{23}$, que pueden asimilarse a las normas que conforman lo que se ha dado por denominar orden público europeo ${ }^{24}$.

En este orden de ideas, la práctica de los órganos supervisores de derechos humanos en el ámbito comunitario, también está promoviendo hacia la conformación de dicho orden público partiendo de la idea de que en cuya base se encuentran ciertos valores y principios fundamentales de la comunidad internacional y de la Unión Europea, mismos que a la fecha, ya no dependen de los Estados para ser aplicados o derogados. ${ }^{25} \mathrm{~A}$ este conjunto de normas son las que podríamos identificar como integrantes de ese orden público comunitario.

Finalmente, es de destacar que con motivo de la suscripción por la Unión Europea de varios acuerdos comerciales donde se incluyen numerosas cláusulas de derechos humanos ${ }^{26}$, estas acciones han contribuido a la conformación de lo que se denomina orden público internacional hacia el interior de la Unión.

\section{LAS NORMAS DE DERECHOS HUMANOS CONVENCIONALES COMO PARTE DE UN ORDEN PÚBLICO GENERAL}

Es evidente que, dados los contenidos de las normas de derechos humanos convencionales e internacionales, sus efectos jurídicos son sui géneris tanto a nivel nacional como supranacional. De inicio, son normas del tipo erga omnes, por lo que tal parece que se extienden como un haz de derechos y obligaciones tanto para las Partes como

${ }^{22}$ LÓPEZ HuRTADO, c., ¿Un régimen especial para los tratados de derechos humanos dentro del Derecho Internacional?, cit., pp. 283 y 284.

${ }^{23}$ HeRdegen, cit., p.49.

${ }^{24}$ GonZÁlez GonZÁLEZ, Rossana, «Límites a la construcción de un «orden público europeo» en materia de derechos fundamentales (a propósito de la sentencia del TJCE Krombach c. Bamberski, de 28 de marzo de 2000)», Revista de Derecho Comunitario Europeo, N. ${ }^{\circ}$ 8, Julio- diciembre, 2000, pp. 593-617. Texto disponible en http:// www.cepc.es/rap/Publicaciones/Revistas/4/RDC_008_217.pdf

${ }^{25}$ LóPEz HuRTAdo, C., ¿Un régimen especial para los tratados de derechos humanos dentro del Derecho Internacional?, cit., p. 286.

${ }^{26}$ Cfr. NIEDRIst, Gerhard, "Las cláusulas de los derechos humanos en los tratados de libre comercio de la Unión Europea», Anuario Mexicano de Derecho Internacional, vol. XI, Editado por el Instituto de Investigaciones Jurídicas de la UNAM, México, 2011, pp. http://biblio.juridicas.unam.mx/estrev/pdf/derint/cont/11/cmt/cmt16.pdf 
para numerosos terceros (Estados, organizaciones o individuos) ajenos a la relación jurídica convencional.

Visto así, las normas convencionales internacionales de derechos humanos son parte de «acuerdos internacionales que contienen disposiciones normativas para promover o proteger uno o más Derechos Humanos ${ }^{27}$ y tienen características particulares que los diferencian sustancialmente de los demás instrumentos jurídicos de su género, es decir, de cualquier tratado internacional, por lo que por su contenido, no pueden encontrarse sujetos al mismo régimen jurídico que un tratado internacional general, ni a nivel nacional ni internacional.

Tampoco consideramos que les pueda resultar aplicable, en forma absoluta, las reglas previstas en la Convención de Viena de 1969 sobre el Derecho de los Tratados celebrados entre Estados, dado el enorme desarrollo y relevancia que han adquirido este tipo de normas convencionales. Debiéndose, en todo caso, contar con una regulación ad hoc que, en principio, tenga como criterios interpretativos rectores el objeto y fin que los mismos tratados persiguen.

Esta sería otra característica de la normas convencionales que forman parte de ese orden público internacional, esto es, normas convencionales que si bien originalmente fueron objeto de negociación debido a su evolución y reconocimiento han adquirido una gran relevancia y han pasado de ser normas dispositivas a normas imperativas a nivel internacional y nacional, amparadas en su reconocimiento como fundamentales por la misma comunidad internacional en su conjunto.

Si bien, en el ámbito internacional, está en todo momento presente la responsabilidad internacional del Estado y de algunos otros sujetos de derecho internacional, típicos o atípicos, por la violación a normas internacionales de derechos humanos, también es indudable que hoy en día, la falta de protección o afectación a tales derechos dentro de los ordenamientos internos, también puede dar paso a una responsabilidad mayor, además de la internacional, de carácter civil, penal $^{28} \mathrm{o}$ administrativa de varios sujetos relacionados con el caso de que se trate, y es ahí en dichas consecuencias jurídicas donde pode-

${ }^{27}$ Cfr. San Miguel Aguirre, Eduardo, Derechos Humanos, legislación nacional y tratados internacionales, 1. ${ }^{a}$ edición, México, Editado por la Comisión Nacional de los Derechos Humanos (CNDH), 1994, p. 13. Cfr. García RamíreZ, Sergio, en su Comentario al libro de Rodríguez HuerTa, Tania Gabriela, Tratados sobre derechos humanos, El sistema de reservas, $1 .^{\text {a }}$ Edición, México, Editado por el Instituto Tecnológico Autónomo de México y Editorial Porrúa, 2005, p. XIX.

${ }^{28}$ CEBADA Romero, Alicia, «Los conceptos de obligación erga omnes, ius cogens y violación grave a la luz del nuevo proyecto de la CDI sobre responsabilidad de los 
mos encontrar elementos comunes, en ambos órdenes jurídicos, cuyos efectos, bien podrían ser calificados como de orden público general, es decir, que resultan aplicables en todo sistema jurídico.

Además de lo anterior, transgresiones de este tipo, generalmente, pueden activar no sólo la participación de las jurisdicciones nacionales o internacionales competentes, sino también propiciar la puesta en marcha de algún mecanismo protector o supervisor de derechos humanos a fin de vigilar, en su momento, el cumplimiento de las resoluciones o decisiones internacionales dictadas. Evidentemente, lo anterior, puede ser un botón de muestra de que estas normas comunes, de alguna manera, mueven hacia la coordinación, colaboración, armonización y sincronización entre los órdenes involucrados para la prosecución de un mismo fin, que es la protección de los derechos humanos y el resarcimiento a las víctimas. Creemos que este fenómeno es una clara expresión de las normas de orden público internacional.

Jordi Palou Loverdos destaca que el principio de la «prevención general» ha contribuido a la determinación y consenso de conductas consideradas prohibidas y graves. Asimismo, de forma indirecta, ha conducido a la afirmación de los valores sociales colectivos recogidos por el Derecho para facilitar la paz social e internacional, y que como ejemplo tenemos la aceptación del principio de justicia universal y su incorporación a los ordenamientos internos. ${ }^{29}$ Este principio, creemos

estados por hechos ilícitos», Revista Electrónica de Estudios Internacionales, http:// www.reei.org/reei4/Cebada. PDF

${ }_{29}$ «La regulación y el enjuiciamiento de estos crímenes, que afectan a toda la humanidad, no sólo es importante para acabar con la impunidad que han disfrutado históricamente los criminales genocidas, criminales de lesa humanidad, criminales de guerra y terroristas de estado que han masacrado y subyugado a pueblos enteros -en su mayor parte, población civil inocente-, sino, también y sobre todo, como realización del principio liberal jurídico-penal de la prevención general propuesto hace casi dos siglos por Feuerbach y Bentham y recogido ampliamente por la doctrina jurídico-penal. Me refiero al aspecto negativo de la "prevención general», esto es, la intimidación -ahora ya globalizada- de que estos crímenes no quedarán sin castigo en la jurisdicción nacional o internacional que sea competente, y que sus responsables deberán, tarde o temprano, responder ante sí y ante la comunidad internacional por sus atroces crímenes, resultando cada vez más difícil que estos criminales se paseen libremente por el mundo sin miedo a ser inquietados o detenidos cuando van a recoger fuera de sus países de origen el producto del expolio que a menudo tienen depositado en cuentas bancarias o cajas de seguridad en el extranjero. Pero me refiero también al aspecto positivo de la referida prevención general, a la función informativa de las conductas que están prohibidas y de la afirmación de los valores sociales colectivos recogidos por el Derecho para facilitar la paz social, en este caso internacional.» PALOU Loverdos, Jordi, Crímenes de guerra contra españoles, ruandeses y congoleses en áfrica central (1990-2006): El conflicto de los grandes lagos desde la perspectiva de los derechos humanos y el Derecho Internacional humanitario, p. 6, www.rei.org. 
que indudablemente también es parte integrante de ese conjunto de normas que conforman el orden público general.

Está visto que hoy en día, las normas de derechos humanos en tanto integrantes del orden público internacional pueden limitar al Estado en cuanto a invocar el principio de reciprocidad o el derecho de denuncia de un tratado por su violación, si es de derechos huma$\operatorname{nos}^{30}$, así como también el limitar la voluntad soberana de los Estados, y de su poder constituyente en la creación de normas:

... supremacía del bien común internacional sobre el bien común nacional, afectando el sentido y alcance de la soberanía estatal. Así se bosqueja una nueva estructura de poder supranacional y supraestatal, generándose un orden público internacional y supraestatal cada día más evidente. Este tiene como sujeto básico la dignidad de la persona y tiene como fin el reconocimiento, garantía y promoción efectiva de los derechos humanos, tal como los ha definido la comunidad internacional y los órganos reguladores de los sistemas de protección del Derecho Internacional de los derechos humanos. ${ }^{31}$

Esto es porque, por los contenidos, fines y valores comunes que importan dichas normas, se pueden establecer puntos de conexión entre los diferentes ordenamientos jurídicos existentes ${ }^{32}$ propiciando así su uniformidad y armonía.

Finalmente, parafraseando un poco a Nash podemos destacar que a fin de alcanzar ese corpus iure de protección, o ese orden público internacional compuesto de normas superiores, es que se debe mirar a los diferentes sistemas jurídicos como una integralidad donde normas, instituciones y prácticas jurisprudenciales permitan al individuo la posibilidad de invocar tanto en el plano nacional como supranacio-

${ }^{30}$ Tales como el principio del pacta sunt servanda, la libre autodeterminación de los pueblos o el ejercicio absoluto de la soberanía nacional de los Estados, por citar los más relevantes.

${ }^{31}$ Nogueira Alcalá, Humberto, Constitución y Derecho Internacional de los Derechos Humanos, Chile, Editorial Librotecnia, 1999, p. 654.

${ }^{32}$ En ese sentido se manifiesta César Sepúlveda cuando señala: «Existe gran afinidad entre las ramas mencionadas -Derecho Internacional humanitario, derechos del hombre y la protección internacional a los refugiados- porque las tres obedecen a las mismas razones, o sea, la protección a la persona humana en su integridad y en sus derechos básicos. Todas ellas buscan, por métodos un tanto diferentes, aliviar la suerte de seres infortunados, que por acción del Estado o de sus agentes, por los conflictos armados internos o internacionales, por el temor a la violencia que los rodea, o huyendo de calamidades, son víctimas de circunstancias que producen la necesidad de protegerlos, siempre con fundamento en normas jurídicas. El elemento común de estos tres brazos es el respeto a la persona humana.» SEPÚLVEDA, César, Estudios sobre Derecho Internacional y Derechos Humanos, 2. ${ }^{a}$ edición, México, Comisión Nacional de los Derechos Humanos, 2000, p. 174. 
nal, la normativa constitucional e internacional en materia de derechos humanos, así como recurrir expeditamente a la instancia jurisdiccional nacional o internacional ${ }^{33}$ competente para la satisfacción de sus demandas.

\section{BREVES CONSIDERACIONES EN TORNO AL CONTENIDO DEL ORDEN PÚBLICO INTERNACIONAL}

Para Santiago Pagliari existe una coincidencia a nivel internacional de que a la fecha hay ciertas normas que conforman el llamado orden público internacional ${ }^{34}$. Ya vimos que esas normas que podrían conformar el orden público internacional son un tipo de normas consideradas fundamentales, comunes y generalmente asociadas a contenidos de derechos humanos; sin embargo, cabría ahora preguntarnos si en realidad este orden público como ya lo concebimos es propio o exclusivo del orden internacional y si, las normas que lo conforman, en tanto que se trata de normas comunes a todo sistema jurídico, pueden conformar un solo bloque o núcleo del derecho. Es decir, si en tanto integrantes del orden público internacional, dichos contenidos pueden ser igualmente aplicables a todo ordenamiento jurídico nacional o supranacional. Creemos que sí puede ser el caso, y en esa tesitura estaríamos refiriéndonos al orden público general.

En consecuencia, la denominación de orden público internacional, como aparece ahora, podría no resultar del todo correcta, pues parecería referida exclusivamente al orden internacional, mientras que el orden público general estaría referenciado a todo sistema jurídico existente, razón por la cual nos parece un concepto más adecuado.

En consecuencia, el «orden público general» ya no se limitaría al ámbito internacional sino a todo sistema jurídico en general, sin importar el orden de que se trate: nacional, internacional, comunitario, local, regional, provincial o autonómico.

No obstante que al orden público se le ha definido como «el conjunto de normas y principios que, en un momento histórico determinado, reflejan el esquema de valores esenciales a cuya tutela atiende

${ }^{33}$ Nash Rojas, C., La protección Internacional de los Derechos Humanos, cit., pp. 227 y 228.

${ }^{34}$ Santiago Pagliari, Arturo, «El Derecho Internacional público, funciones, fuentes, cumplimiento y la voluntad de los estados», Anuario Mexicano de Derecho Internacional, 1. ${ }^{a}$ ed., vol. IV, Editado por el Instituto de Investigaciones Jurídicas, UNAM, México, 2004, (pp. 457-473), p. 466. http://www.bibliojuridica.org/estrev/pdf/derint/ cont $/ 4 / \mathrm{cmt} / \mathrm{cmt} 15 . \mathrm{pdf}$ 
de una manera especial cada ordenamiento jurídico concreto» ${ }^{35}$, hemos visto también que hay una opinión general de considerar al orden público ${ }^{36}$ como conformado principalmente por normas de derechos humanos, pero no en exclusiva, de ahí que podríamos incluir también normas con contenidos relativos a Principios Fundamentales de Derecho Internacional, Principios Generales del Derecho o conceptos jurídicos fundamentales, normas esenciales con las cuales se hace posible la protección y funcionamiento de cualquier sistema jurídico en general fundado en la protección y respeto a los derechos humanos, bien a nivel individual o grupal.

Además de lo anterior, consideramos que el orden público general, en tanto instrumento jurídico, debe también tener una función preponderante, a saber, garantizar un estándar mínimo de derechos en todo orden jurídico en el que actúe, y por tanto, este orden público no puede ser ajeno ni desconocer principios jurídicos fundamentales y esenciales tanto del Derecho Nacional como supranacional, entre los que indudablemente, también se encuentre la soberanía de los Estados ${ }^{37}$, la libre autodeterminación de los pueblos, la no injerencia en los asuntos internos de los Estados ${ }^{38}$, la solución pacífica de los conflictos o controversias, y el respeto a los derechos humanos, por citar los más relevantes.

Es así que, el orden público internacional, en el orden nacional es una limitante al actuar del Estado y de los individuos frente a los derechos humanos, y lo mismo en el ámbito supranacional, así como un instrumento garante de la existencia y mantenimiento de cualquier sistema jurídico en general, independientemente del orden de que se trate.

${ }^{35}$ Pérez Vera, Elisa, «El concepto de orden público en el Derecho Internacional», en Anuario Hispano-Luso-Americano de Derecho Internacional, no. 7, 1984, pp. 273288

${ }^{36}$ De Rosas, Pablo Enrique, «Orden público internacional. Tendencias contemporáneas. Orden público en el ordenamiento del Mercosur», Boletín de la Facultad de Derecho, UNED, Núm. 22, España, 2003, pp. 193 a 220. http://e-spacio.uned.es/fez/ eserv.php?pid=bibliuned: bfd-2003-22-e63cc2cd\&dsid=pdf

${ }^{37}$ AlCAIDE FERNÁNDEZ, Joaquín, «Orden público y Derecho Internacional: Desarrollo normativo y déficit institucional», en Soberanía del Estado y Derecho Internacional. Homenaje al profesor Juan Antonio Carrillo Salcedo, T. 1, Universidad de Córdoba, Universidad de Sevilla y Universidad de Málaga, España, 2005, pp. 91 a 116.

${ }^{38}$ En la sentencia del Tribunal Constitucional 43/1986, Jurisprudencia constitucional, Número de referencia: 43/1986, Referencia número: 43/1986 (Sentencia), Fecha de Aprobación: 15/4/1986, Publicación BOE: 29/4/1986, Sala: Sala Primera Excmos. Sres. Tomás, Rubio, Díez-Picazo, Truyol, Díaz y Rodríguez-Piñero, Ponente: don Antonio Truyol Serra, Número registro: 325/1985, Recurso tipo: Recurso de amparo. http://www.boe.es/aeboe/consultas/bases_datos/doc.php?coleccion=tc\&id=SENTENC IA-1986-0043 
Visto así, el orden público general se puede asimilar a la existencia de ciertas normas jurídicas que contienen principios fundamentales y comunes, que constituyen un límite al actuar de todos y cada uno de los miembros o sujetos con personalidad jurídica, bien sean del orden nacional o supranacional, tales como el individuo, grupos sociales, los Estados, las organizaciones internacionales, etcétera, dado que se trata de principios imperativos comunes que no pueden ser transgredidos, y su cumplimiento es ineludible, en tanto que contienen o procuran derechos fundamentales y necesarios para la existencia y bienestar común de la humanidad en su conjunto y en lo individual.

Por todo lo anterior, es que consideramos que el orden público general deberá estar conformado por dos grandes grupos de normas básicas que atienden a dos aspectos fundamentales y que corresponden a los dos estándares del derecho en general: normas de contenidos sustantivos que son los principios y valores que constituyen fines en sí mismos y las normas con principios y valores de carácter procedimental, mismos que completen los primeros, y no por ello, sean considerados menos valiosos.

Las normas sustantivas de orden público general, son aquellas normas cuyos contenidos reflejan derechos sustantivos, son fines en sí mismos, a los que debe tender todo sistema jurídico en general, y constituyen el objeto hacia el cual, deben tender las normas procedimentales o instrumentales del orden público general.

Estas normas sustantivas importan valores absolutos y comunes, es así que tienen contenidos relacionados con derechos humanos básicos, como el derecho a la integridad física, el derecho de las víctimas a ser indemnizadas y a que se les repare el daño causado, por citar algunos ejemplos.

Mientras que, por lo que respecta a las normas denominadas adjetivas o procedimentales, serían aquellas normas que se refieren a la cuestiones relacionadas con la certeza jurídica, el debido proceso, la irretroactividad de las normas y de los tratados internacionales, la garantía de audiencia, etcétera. Normas que además van referidas a la prosecución de otros valores sustantivos como las normas de derechos humanos.

Es evidente que estos tipos de normas son una constante en todo sistema jurídico y son las que brindan el mínimo soporte de orden, legalidad y certeza jurídica que deben tener todo sistema jurídico que se precie de tal. 


\section{CONCLUSIONES}

El orden público, desde sus orígenes, fue un concepto eminentemente proteccionista y político-jurídico, mismo que estaba referido fundamentalmente a la soberanía estatal. Sin embargo, dicho concepto ha variado debido a la evolución y desarrollo tanto a nivel nacional como internacional de las normas de derechos humanos, mismas que han propiciado la conformación de un bloque de normas comunes, esenciales y valiosas para todos los sistemas jurídicos existentes. Asimismo, tales normas han potencializado sus efectos vía la incorporación de tratados internacionales en la materia, tanto en los ordenamientos jurídicos nacionales como a nivel supranacional.

Es así como encontramos que vía la suscripción de tratados internacionales en esta materia, los diferentes ordenamientos jurídicos existentes, tienen ya como eje rector la protección de los derechos del individuo, elemento que incide una manera significativa en el actuar del Estado así como de los demás actores internacionales tanto nivel nacional como supranacional, limitando su capacidad de acción a la luz de un concepto nuevo que se denomina el orden público internacional, mismo que debiera llamarse orden público general, dado que las normas que lo conforman son comunes y no se circunscriben sólo al ámbito internacional.

Estas normas que hoy se consideran de orden público general, si bien están conformadas en su mayoría por normas de derechos humanos, indudablemente tienen un denominador común, a saber, son normas básicas y fundamentales, que gozan de un reconocimiento universal y valor absoluto en todo sistema jurídico existente.

Por tanto, podemos definir al orden público general como un conjunto de normas básicas, esenciales y fundamentales, comunes a todo sistema jurídico existente, y que son consideradas valiosas y por ende vinculantes. Asimismo, dado su reconocimiento general, éstas conectan e interrelacionan a los diferentes ordenamientos jurídicos existentes, impulsando o propiciando así la armonización de sus relaciones y sentando las bases para la conformación de una normativa uniforme y homogénea.

Asimismo, su principal efecto jurídico consiste en limitar el actuar de los diferentes sujetos o actores nacionales e internacionales, en aras de tutelar los derechos fundamentales y esenciales propios de todo ser humano. 


\section{BIBLIOGRAFÍA}

AGUILAR CAVALLO, Gonzalo, «La Corte Interamericana de Derechos Humanos y los derechos sociales», Revista Iberoamericana de Derecho Procesal Constitucional, número 13, enero-junio, Editada por el Instituto Iberoamericano de Derecho Procesal Constitucional, México, 2010.

ALEXY, Robert, Teoría de los derechos fundamentales, versión castellana: Ernesto Garzón Valdés, revisión: Ruth Zimmerling (Título original: Theorie der GrundRechte), Madrid, Centro de Estudios Constitucionales, 1997.

BOBBIO, Norberto, El problema de la guerra y las vías de la paz, trad. de Jorge Binahi, Primera edición, Barcelona, Editorial Gedisa, 1982.

CANÇADO TRINIDADE, Antonio Augusto, Derecho Internacional de los Derechos Humanos, esencia y trascendencia, Votos de la Corte Interamericana de Derechos Humanos, 1991-2006, México, Editorial Porrúa y Universidad Iberoamericana, 2007.

CARMONA TINOCO Jorge Ulises, El significado de la aceptación de la competencia de los comités de Naciones Unidas, facultados para decidir peticiones individuales en materia de derechos humanos y su previsible impacto en la impartición de justicia en México, en Reforma Judicial, Revista Mexicana de Justicia, No. 1, enero-junio, 2003, Editado por el Instituto de Investigaciones Jurídicas de la UNAM, México.

CARPIZO, Enrique, Derechos fundamentales, Interpretación constitucional. La Corte y los Derechos, 1. a edición, Editado por el Instituto Mexicano de Derecho Procesal Constitucional y Porrúa, México, 2009.

GROSS ESPIELL, H., "Los derechos humanos: el derecho constitucional y el Derecho Internacional», en Problemas actuales del Derecho Constitucional, Estudios en homenaje a Jorge Carpizo, México, UNAM, Instituto de Investigaciones Jurídicas, 1994.

CEBADA ROMERO, Alicia, «Los conceptos de obligación erga omnes, ius cogens y violación grave a la luz del nuevo proyecto de la CDI sobre responsabilidad de los estados por hechos ilícitos», Revista Electrónica de Estudios Internacionales.

DE ROSAS, Pablo Enrique, «Ponencia Orden público internacional. Tendencias contemporáneas. Orden público en el ordenamiento 
del Mercosur», en XXVI Seminario Nacional de Derecho Internacional Privado y Comparado, Profr. Friedrich K. Juenguer, Academia Mexicana de Derecho Internacional Privado y Comparado, A. C., México, Universidad Iberoamericana de Tijuana, México, http:// www.amedip.org/pdf/DeRosasPabloEnrique. PDF

DEL TORO HUERTA, Mauricio Iván, «El principio de subsidiariedad en el Derecho Internacional de los Derechos Humanos con especial referencia al sistema interamericano», en Becerra Ramírez, Manuel (coord.), La Corte Interamericana de Derechos Humanos a Veinticinco años de su funcionamiento, México, UNAM, Instituto de Investigaciones Jurídicas, 2007, http://biblio.juridicas.unam. $\mathrm{mx} / \mathrm{libros} / 5 / 2496 / 7 . p d f$

KAMTO, Maurice, "Volonté de l'État et ordre public International», Recueil des Cours de Droit International, tomo 310, París, 2004.

KELSEN, Hans, El contrato y el tratado, analizados desde el punto de la Teoría pura del derecho, 2. ${ }^{a}$ edición, México, Editorial Colofón.

LA PÉRGOLA, Antonio, Constitución del Estado y normas internacionales, 1. ${ }^{a}$ edición, traductores José Luis Cascajo Castro y Jorge Rodríguez-Zapata Pérez, México, Editado por el Instituto de Investigaciones Jurídicas de la UNAM, 1985.

MARTÍN ARRIBAS, Juan José, «Hacia un Derecho Internacional global en los albores del siglo XXI», en Anuario de Derecho Constitucional Latinoamericano, tomo II, año 11, Editado por Fundación Konrad-Adenuaer-Stinftung E. V., Uruguay, 2005.

MEZGRAVIS, Andrés A., «El orden público sustantivo, el orden público procesal y la arbitrabilidad como causales de denegación del laudo: especial referencia a Venezuela y otros países de América Latina», en Arbitraje Comercial y Arbitraje de Inversión, la Convención de NY 50 años después, Instituto Peruano de Arbitraje, Perú, 2009.

NASH ROJAS, Claudio, «La protección Internacional de los Derechos Humanos, Chile, publicado por el Centro de Derechos Humanos de la Universidad de Chile, 2006», versión corregida de las conferencias dictadas en el marco del Seminario Internacional, El Sistema Interamericano de Protección de los Derechos Humanos y su repercusión en los órdenes jurídicos nacionales, organizado por la Corte Interamericana de Derechos Humanos y la Suprema Corte de Justicia de México, dirigida a funcionarios de la Suprema Corte, México D. F., (1 y 2 de febrero 2006). 
RODRÍGUEZ HUERTA, T. G., Tratados sobre derechos humanos, El sistema de reservas, 1. ${ }^{a}$ Edición, México, Editado por el Instituto Tecnológico Autónomo de México y Editorial Porrúa, 2005,

SAN MIGUEL AGUIRRE, Eduardo, Derechos Humanos, legislación nacional y tratados internacionales, 1 a $^{\text {a }}$ edición, México, Editado por la Comisión Nacional de los Derechos Humanos (CNDH), 1994.

SOLARI IRIGOYEN, Hipólito, «Las reservas a los Tratados Internacionales de Derechos Humanos, Estos tratados son de naturaleza distinta al resto de los acuerdos internacionales, por lo que las reservas deben ser más limitadas», Revista Agenda internacional, Año 2, Número 8, Marzo/Abril/Mayo/Junio, Argentina, 2006.

VARÓN MEJÍA, Antonio, «Orden público internacional y normas «ius cogens»: una perspectiva desde la comisión de Derecho Internacional y la Convención de Viena de 1969», en Diálogos de saberes: investigaciones y ciencias sociales, Universidad Libre, ISSN 01240021, N. ${ }^{\circ}$ 32, Colombia, 2010.

\section{Jurisprudencia internacional y supranacional}

CORTE EUROPEA DE DERECHOS HUMANOS, Sentencia de 18 de enero de 1978, Caso Irlanda contra Reino Unido de Gran Bretaña, párrafo 239, Série A, n. ${ }^{\circ} 25$.

CORTE INTERAMERICANA DE DERECHOS HUMANOS, Opinión Consultiva 2/82 de la Corte Interamericana de Derechos Humanos. El efecto de las reservas, sobre la entrada en vigor de la Convención Americana de Derechos Humanos (art. 74 y 75), de 24 de septiembre de 1982 .

CORTE INTERAMERICANA DE DERECHOS HUMANOS, Caso Radilla Pacheco VS. Estados Unidos Mexicanos, Sentencia de 23 de noviembre de 2009, (Excepciones Preliminares, Fondo, Reparaciones y Costas).

CORTE INTERAMERICANA DE DERECHOS HUMANOS, caso Velásquez Rodríguez Vs. Honduras, Excepciones preliminares, de 26 de junio de 1987.

- Resolución del Presidente de la Corte Interamericana de Derechos Humanos, de 7 de julio de 2011, Caso Atala Riffo e hijas vs. Chile.

- Opinión Consultiva OC-5/85, del 13 de noviembre de 1985, La Colegiación obligatoria de periodistas (artículos 13 y 29 de la Con- 
vención Americana sobre Derechos Humanos) solicitada por el Gobierno de Costa Rica.

CORTE INTERNACIONAL DE JUSTICIA, Barcelona Traction, Light and Power Company, Limited, Judgment, ICJ Reports, 1970.

\section{Instrumentos jurídicos internacionales}

Convención Americana sobre Derechos Humanos

Convención sobre la Eliminación de todas las Formas de Discriminación contra la Mujer

Convención sobre los Derechos del Niño

Declaración y Programa de Acción de Viena.

Estatuto de Roma

Observación General $N^{\circ} 24$, aprobada en el $52^{\circ}$ período de sesiones, en 1994.

Pacto Internacional de Derechos Civiles y Políticos

Resolución del Consejo de Seguridad de las Naciones Unidas, No. 688 de 1991, de fecha 5 de abril de 1991,

\section{Direcciones de internet}

http://www.reei.org/reei4/Cebada. PDF

http://www.bibliojuridica.org/libros/libro.htm?l=433

http://www.cdh.uchile.cl/media/publicaciones/pdf/27.pdf

http://www.acnur.org/biblioteca/pdf/1981.pdf

http://www.corteidh.or.cr/docs/casos/articulos/seriec_209_esp.pdf

http://dialnet.unirioja.es/servlet/articulo?codigo=3295808

http://www.juridicas.unam.mx/publica/rev/refjud/cont/1/cle/cle14.htm http://www.corteidh.or.cr/docs/opiniones/seriea_02_esp.pdf

http://www.agendainternacional.com/numerosAnteriores/n8/0803.pdf http://www.mezgravis.com/El-orden-pub-vf-rev-07-08.pdf

http://www.corteidh.or.cr/docs/asuntos/atala.pdf

http://www.corteidh.or.cr/docs/opiniones/seriea_05_esp.pdf

(C) UNED. Revista de Derecho UNED, núm. 14, 2014 
